Research Article

\title{
Study on the Mine Pressure Law and the Pressure Frame Mechanism of an Overlying Goaf in a Shallow Coal Seam
}

\author{
Haifeng Zhou, ${ }^{1,2}$ Qingxiang Huang, ${ }^{1}$ Yingjie Liu $\mathbb{D}^{\mathrm{D}},{ }^{3}$ and Yanpeng $\mathrm{He}^{1}$ \\ ${ }^{1}$ College of Energy Engineering, Xi'an University of Science and Technology, Xi'an 710054, China \\ ${ }^{2}$ Bulianta Coal Mine, China Energy Shendong Coal Group, Shenmu 719315, China \\ ${ }^{3}$ China Academy of Coal Science of CCTEG, Beijing 100013, China
}

Correspondence should be addressed to Yingjie Liu; 290783585@qq.com

Received 28 April 2021; Accepted 18 August 2021; Published 8 September 2021

Academic Editor: Feng Du

Copyright (C) 2021 Haifeng Zhou et al. This is an open access article distributed under the Creative Commons Attribution License, which permits unrestricted use, distribution, and reproduction in any medium, provided the original work is properly cited.

To study the problems of dynamic load pressure and frame pressure caused by the concentration of stress by coal extraction pillars during the mechanized short-distance mining of goaves in shallow coal seams, a frame pressure accident, in the Shendong Shigetai Coal Mine, during the overlying of a fully mechanized mining goaf is taken as a research example. By applying the field measurement, theoretical analysis, and numerical simulation methods, we throughly analysed the working face coal pillar, got the regular pattern of fully mechanized overburden pressure, summarized a pillar of fully mechanized working face in the overburden strata movement regularity and development characteristics, analyzed the reason and mechanism of broken coal pillar, and put forward the corresponding prevention measures and management method. The results show that when the fully mechanized mining face enters the goaf by about $3 \mathrm{~m}$, the pressure arches of the lower coal face and the upper goaf arising from the extracted coal overlap. When the vertical stress is greater than the supporting force of the hydraulic support and the coal wall, a roof ejection accident may occur.

\section{Introduction}

The coal seams in the Shendong mining area in western China are typical shallow coal seams characterized by shallow burial depth, thin bedrock, and thick loose sand soil [1-3]. In the early stages of mining, due to the influence of available mining technology, the geological structure, and the cross-boundary mining of small coal kilns, some mines left many room goaves and pillars in the goaves when mining the first layer of coal [4-6]. With the development of the Shendong mining area, a coal pillar in the upper coal goaf would be gradually transferred to the lower coal seam. There are, as a result, many large-scale roof cuttings and pressing accidents $[7,8]$. According to incomplete statistics, in recent years, there have been many accidents involving concentrated coal pillar pressing in the upper overburden goaves in fully mechanized faces $[9,10]$. This is a major problem that restricts the normal safety of mine production, as the fully mechanized face is overlaid by a goaf and concentrated coal pillars [11].
Many researchers in China have studied the mechanisms of pressure frames and the control measures of the overlying concentrated coal pillars in fully mechanized coal mining faces of shallow coal seams. Based on the study of coal pillars in multiseam mining in a Shigetai coal mine and the classification of coal seam groups $[12,13]$. The researchers found that when a comprehensive mining face is close to the overlying coal pillar, the change in the large structure will cause the range of the lower small structure rock layers to increase exponentially, where the stress states of the small structure rock stratum change from tension to shear, and the load-bearing of the microstructures increases greatly, while the microstructure integrity is destroyed. This then leads to examples of events such as a change in the large structure frame pressure accident $[14,15]$. $\mathrm{Xu}$ et al. analyzed the instability mechanism and the pressure frame mechanism of the key layer structure when shallow coal seam faces were covered with concentrated coal pillars [16-18]. Ju et al. analyzed the pressing mechanism by using the key layer 
theory and proposed prevention measures such as the preexcavation of the roadway or preblasting at the coal pillar boundary, the filling of the uncompacted goaf at the coal pillar boundary, and the preblasting and strong blasting of the key layer block structure above the coal pillar boundary [19-21]. Li et al. put forward the control measure of blasting in coal pillars [22-24]. Some experts studied weak and hard roofs under the influence of directional hydraulic fracturing and compared this with the blasting method. It is seen that the effect of directional hydraulic fracturing is obvious [25-28]. The mechanical mechanism of directional hydraulic fracturing is comprehensively analyzed and the controllable roof caving is realized [29-31].

Based on the back pressing accident of the 22306 fully mechanized mining face in the Shendong Shigetai coal mine, this paper examines the mechanisms associated with the dynamic load back pressing frame of hole cutting through the upper coal seam (i.e., the 22 upper coal seam, 301 fully mechanized mining face) in a fully mechanized mining face. The corresponding countermeasures are put forward to provide a reference for the safe operation of fully mechanized mining faces under similar conditions.

\section{Mining Conditions and Support Pressing Process}

2.1. Overview of Working Face. The width of the 22306 fully mechanized working face in the Shigetai coal mine is $286.6 \mathrm{~m}$, the advancing length is $5096.6 \mathrm{~m}$, the dip angle of the coal seam is between $1^{\circ}$ and $3^{\circ}$, the burial depth is between 80 and $102 \mathrm{~m}$, the thickness of the bedrock is from 30 to $81 \mathrm{~m}$, and the thickness of the loose layer is from 7.8 to $62.5 \mathrm{~m}$. The burial depth is $150 \mathrm{~m}$ and the mining height is $2.1 \mathrm{~m}$. The direct roof of the working face is sandy mudstone and fine-grained sandstone with a thickness of 2.3 to $7.8 \mathrm{~m}$ and an average thickness of $5.3 \mathrm{~m}$. The main roof is mediumgrained sandstone, fine-grained sandstone, and siltstone with a thickness of 6.8 to $21.3 \mathrm{~m}$ and an average thickness of $14.2 \mathrm{~m}$. The working face is equipped with 168 sets of zy9200/12.3/22.3d hydraulic supports. When the 22306 working face advances $4189.6 \mathrm{~m}$, it enters into the overlying 22-upper-301 fully mechanized mining face, where the distance from the 22 upper coal seam is between 8.8 and $17.7 \mathrm{~m}$, and the influence range is from the machine head to 155 hydraulic support. The borehole histogram of the 22306 working face in the Shigetai mine is shown in Figure 1.

The width of the 22 upper coal seam, 301 fully mechanized mining face is $300 \mathrm{~m}$, the advancing length is $544 \mathrm{~m}$, the coal seam inclination angle is between $1^{\circ}$ and $3^{\circ}$, the burial depth is from 70 to $82 \mathrm{~m}$, the mining height is $2.1 \mathrm{~m}$, and there is an overall negative slope. The mining time is from May to September 2015. The direct roof of the working face is fine-grained sandstone and coarse-grained sandstone with a thickness of 1.5 to $8.8 \mathrm{~m}$, with an average of $5.5 \mathrm{~m}$, while the old roof is medium-grained sandstone, siltstone, fine-grained sandstone, and coarse-grained sandstone with a thickness of 9.2 to $19.3 \mathrm{~m}$ and an average of $14.6 \mathrm{~m}$. The relationship in the position of these two working faces is shown in Figure 2.
2.2. Frame Pressing Process. On August 23, 2018, 8 cutters were cut in the middle shift, with the pressure being normal (258 to 320 bar) after 2 cutters. There was no rib spalling on the coal wall and no water drenching on the working face. On August 24, the night shift took over normal production. When the second cutter tail cut triangle coal, 50 to 160 hydraulic supports of the working face suddenly came under pressure, with a pressure range of 7939 to $10871 \mathrm{kN}$ (390 to 534 bar). When the coal machine had cut coal until 130 hydraulic support, it was found that the hydraulic support had sunk and the coal machine could not pass through. To prevent the coal machine from being crushed, it was towed to the tail of the coal mining machine (Figure 3 ). At this time, the head of the coal mining machine was $8 \mathrm{~m}$ away from the goaf, with the tail of the machine entering the goaf by $3.3 \mathrm{~m}$, and the working face entered the goaf by 98 to 155 hydraulic supports (57 in total).

When a large area of subsidence occurred in the working face, the mining height of frames 71 to 136 frames was 1.2 to $1.5 \mathrm{~m}$, including frames 108 to 111 and 122 to 130 , which showed the lowest mining height of $1.2 \mathrm{~m}$ (Figure 4 ). The interval between the machine head and the upper repeated working face and the upper 301 working face was between 10 and $17 \mathrm{~m}$. A field inspection was carried out, with the measurements of the ground fissures and an example shown in Figure 5.

To ensure that the 22306 mining face passes through the goaf cut by the 22 upper part mining face smoothly, adjustment measures to any deviations in the process were taken, with the tail side of the machine about $8 \mathrm{~m}$ ahead of the head. After the frame compression, frame 120 showed the farthest surface crack, which was $37.8 \mathrm{~m}$ in advance and $65.1 \mathrm{~m}$ away from the nose of the 22306 mining face, with the surface collapse crack $5 \mathrm{~m}$ to $10 \mathrm{~m}$ away from the working face.

\section{Ground Pressure Behavior Law of Working Face}

The mining pressure monitoring data for the 22306 working face within the range of $4100 \mathrm{~m}$ to $4186 \mathrm{~m}$ are shown in Figure 6. The coal pillar corresponding to the open cut of the 301 mining face on the overlying 22 is the 1 to 155 hydraulic supports. When the working face is advancing $4100 \mathrm{~m}$ to $4133.6 \mathrm{~m}$, the periodic pressure step distance is $8.3 \mathrm{~m}$ to $9.6 \mathrm{~m}$, the pressure continuous distance is $3.2 \mathrm{~m}$ to $6.0 \mathrm{~m}$, and the maximum pressure strength is $59.4 \mathrm{MPa}$, with an average of 33.3 MPa. For the working face push between $4133.6 \mathrm{~m}$ and $4166 \mathrm{~m}$, comparing the areas covered by the sections covered by the 5 to 70 and 75 to 165 hydraulic supports, the cycle pressure law is different. The area covered by the 5 to 70 hydraulic supports is the first area, where the cycle pressure law is normal, and the cycle pressure step distance is from 6.8 to $10.5 \mathrm{~m}$. The 75 to 165 support area is the second region and shows no obvious cycle pressure. Here the compression strength is small, with a maximum compression strength of 47.4 MPa and an average of 29.2 MPa. When the working face advances $416 \mathrm{~m}$, the working face is $15.6 \mathrm{~m}$ away from the 301 surface on the 22 coal seam overburden. The cycle pressure 


\begin{tabular}{|c|c|c|c|c|c|c|}
\hline SN & Name & Petrographic description & Key stratum & Thickness (m) & $\begin{array}{c}\text { Buried } \\
\text { depth }(\mathrm{m})\end{array}$ & Cylindrical \\
\hline 1 & Sand & Dirty yellow, loose. & & 58.10 & 58.10 & \\
\hline 2 & $\begin{array}{l}\text { Fine grained } \\
\text { sandstone }\end{array}$ & $\begin{array}{l}\text { Light gray,argillaceous cement,weathered,see } \\
\text { coal line about } 0.3 \mathrm{~m} .\end{array}$ & & 2.60 & 60.70 & $\begin{array}{ccc}\cdots & \cdots & \cdots \\
\cdots & \cdots & \cdots \\
\cdots & \cdots & \cdots\end{array}$ \\
\hline 3 & 1-2Coal & $\begin{array}{c}\text { Black,stripe brown black,weak asphalt } \\
\text { luster,uneven fracture,ladder coal composition is } \\
\text { mainly dark coal,bright coal,coal type is semi- } \\
\text { dark briquette. }\end{array}$ & & 0.40 & 61.10 & \\
\hline 4 & Pelitic sandstone & $\begin{array}{c}\text { Gray,argillaceous structure,slippery surface } \\
\text { development. }\end{array}$ & & 1.04 & 62.14 & 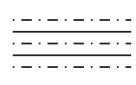 \\
\hline 5 & Siltstone & $\begin{array}{c}\text { Graywhite,argillaceous cement,sandwiced thin } \\
\text { layer of fine sandstone,central calcareous } \\
\text { cement,hard. }\end{array}$ & & 4.64 & 66.78 & $\begin{array}{llll}\cdots & \cdots & \cdots & \cdots \\
\cdots & \cdots & \cdots & \cdots \\
\cdots & \cdots & \cdots\end{array}$ \\
\hline 6 & $\begin{array}{l}\text { Medium grained } \\
\text { sandstone }\end{array}$ & $\begin{array}{l}\text { Graywhite, mainly feldspar and } \\
\text { quartz,argillaceous cementation,local calcareous } \\
\text { cementation,sub-round particles,medium } \\
\text { sorting. }\end{array}$ & Stratum 1 & 10.53 & 77.31 & \\
\hline 7 & 2-2UP coal & $\begin{array}{l}\text { Black,weak asphalt luster,uneven fracture,ladder } \\
\text { - shaped mainly coal components,mainly dark } \\
\text { coal,bright coal. }\end{array}$ & & 1.49 & 78.80 & \\
\hline 8 & Pelitic sandstone & $\begin{array}{l}\text { Gray black,argillaceous cementation,conch- } \\
\text { shaped fracture,fracture to see plant fragments } \\
\text { fossil. }\end{array}$ & & 2.26 & 81.06 & 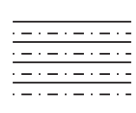 \\
\hline 9 & Siltstone & $\begin{array}{l}\text { Gray white, argillaceous cementation, fracture to } \\
\text { see plant fragments fossil. }\end{array}$ & & 1.31 & 82.37 & $\begin{array}{ccc}\cdots & \cdots & \cdots \\
\cdots & \cdots & \cdots\end{array}$ \\
\hline 10 & $\begin{array}{l}\text { Fine grained } \\
\text { sandstone }\end{array}$ & $\begin{array}{l}\text { Gray white,argillaceous cement,conch-shaped } \\
\text { fracture,containing carbon,thin layer of } \\
\text { calcareous cement in the middle,hard. }\end{array}$ & & 2.87 & 85.24 & 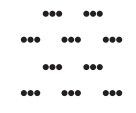 \\
\hline 11 & $\begin{array}{l}\text { Medium grained } \\
\text { sandstone }\end{array}$ & $\begin{array}{c}\text { Gray white,argillaceous cementation,mainly } \\
\text { quartz,feldspar,grain round sub- } \\
\text { angular,medium sorting. }\end{array}$ & Stratum 2 & 9.97 & 95.21 & 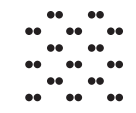 \\
\hline 12 & Pelitic sandstone & Gray argillaceous structure,conch-like fracture, & & 1.03 & 96.24 & 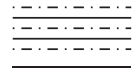 \\
\hline 13 & 2-2Coal & $\begin{array}{c}\text { Black,weak asphalt luster,uneven fracture,step - } \\
\text { shaped mainly coal,the composition is mainly } \\
\text { dark coal,bright coal,coal type is semi-dark } \\
\text { briquette. }\end{array}$ & & 1.86 & 98.10 & \\
\hline 14 & Pelitic sandstone & $\begin{array}{l}\text { Black,argillaceous structure,flat fracture,smooth } \\
\text { surface development,near horizontal bedding. }\end{array}$ & & 11.12 & 109.22 & 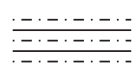 \\
\hline
\end{tabular}

FIgURE 1: Borehole histogram of the 22306 working face in the Shigetai mine.

step within the 1 to 70 hydraulic support section changes a little, while within the 75 to 168 hydraulic support section, the cycle pressure step increases significantly, with the cycle pressure step decreasing to $7.8 \mathrm{~m}$ and the maximum pressure strength is $48 \mathrm{MPa}$ with an average of $34 \mathrm{MPa}$, as shown in Figure 7. Before pressing the frame, the normal section of pressure lasts $6.7 \mathrm{~m}$, and the cycle pressure lasts $3.5 \mathrm{~m}$, so the cycle pressure step distance can be calculated to be $10.2 \mathrm{~m}$.

\section{Numerical Simulations of a Coal Pillar In and Out Stage}

4.1. The Establishment of the Model. The GEDM continuumdiscontinuous element method, proposed by the Institute of Mechanics, Chinese Academy of Sciences, is used to simulate the discontinuous deformation and progressive failure of materials under static and dynamic loads $[32,33]$. According to the KB193 comprehensive column of the 22306 working face, the corresponding numerical model of the advancing direction of the working face is established. The model is $200 \mathrm{~m}$ in length and $123 \mathrm{~m}$ in height, and the overburden layer is applied as a uniformly distributed pressure corresponding to a $60 \mathrm{~m}$ loading layer. The boundary conditions of the simulation model are as follows:

Upper boundary condition: This is related to the loading by the overlying strata. For convenience, the distribution of the load is simplified as a uniform load, and the upper boundary condition is the stress boundary condition, that is, lower boundary condition: The lower boundary condition of the model is the base 


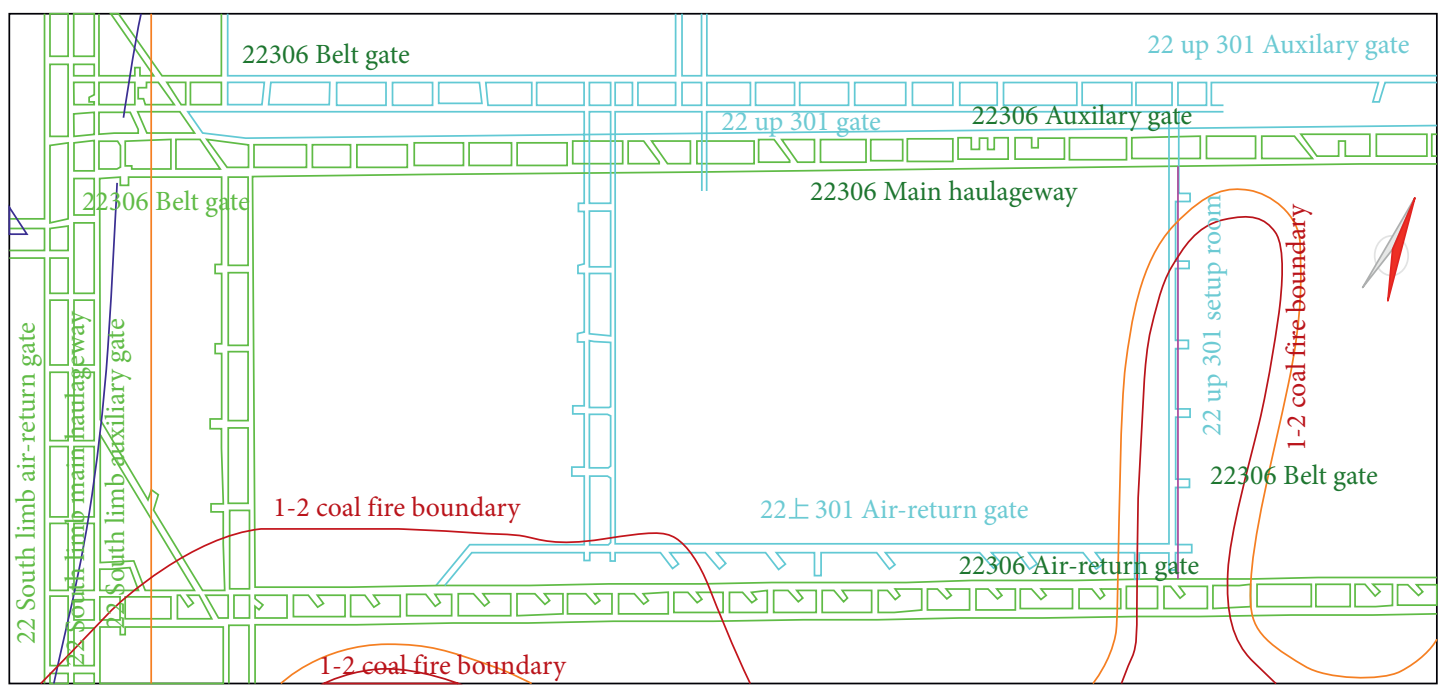

Figure 2: Relative locations of the 22306 mining face and the upper cover 22-upper-301 goaf in the Shigetai mine.

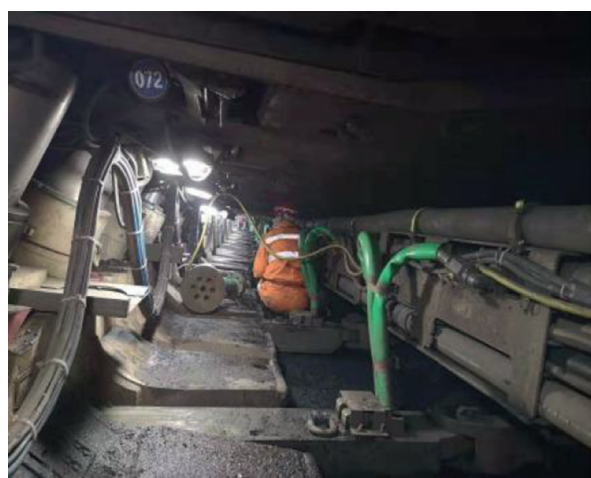

(a)

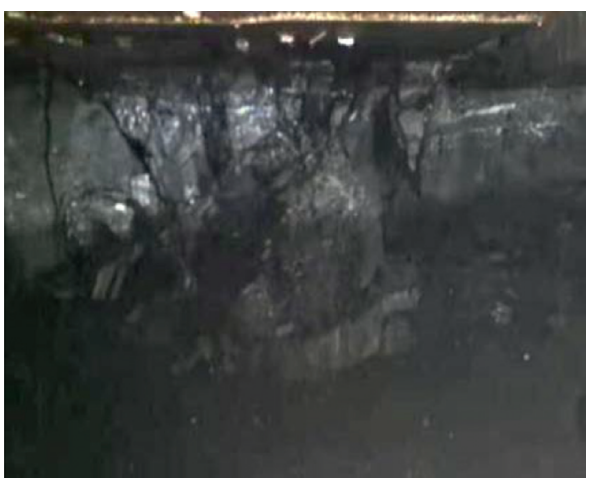

(b)

FIgURE 3: Support crushing and coal wall collapse in the 22306 working face, Shigetai mine.

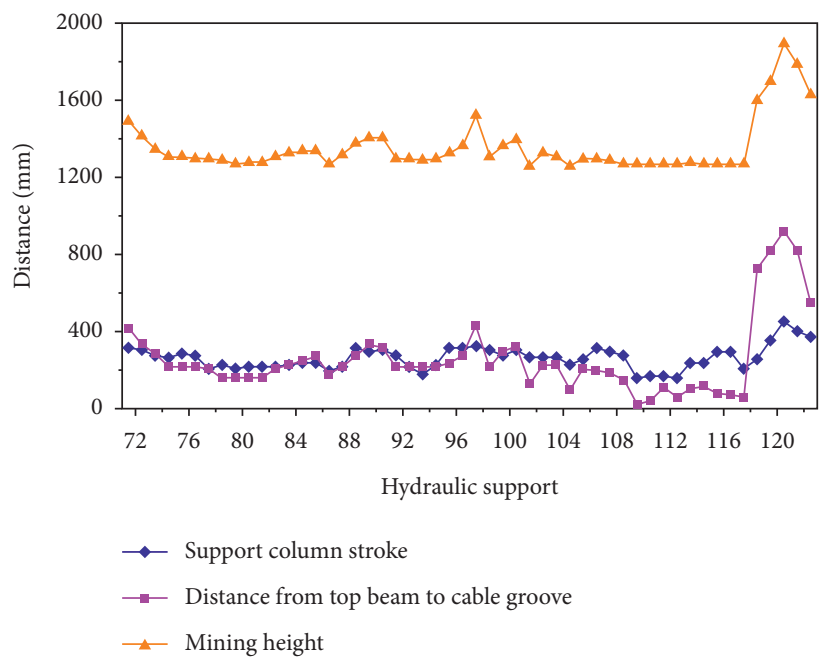

FIGURE 4: Support state (pillar subsidence) curve for the 22306 working face of the Shigetai mine. 


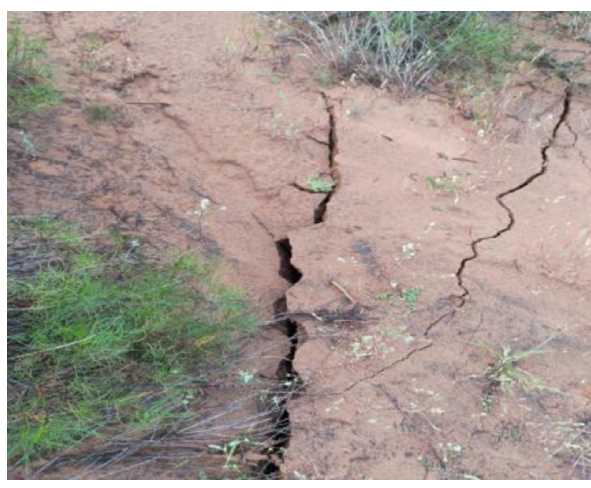

(a)

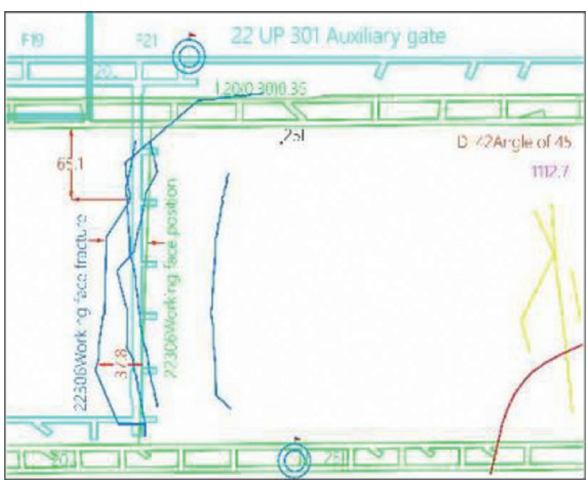

(b)

FIGURE 5: Distribution of surface subsidence cracks in the 22306 working face of the Shigetai mine.

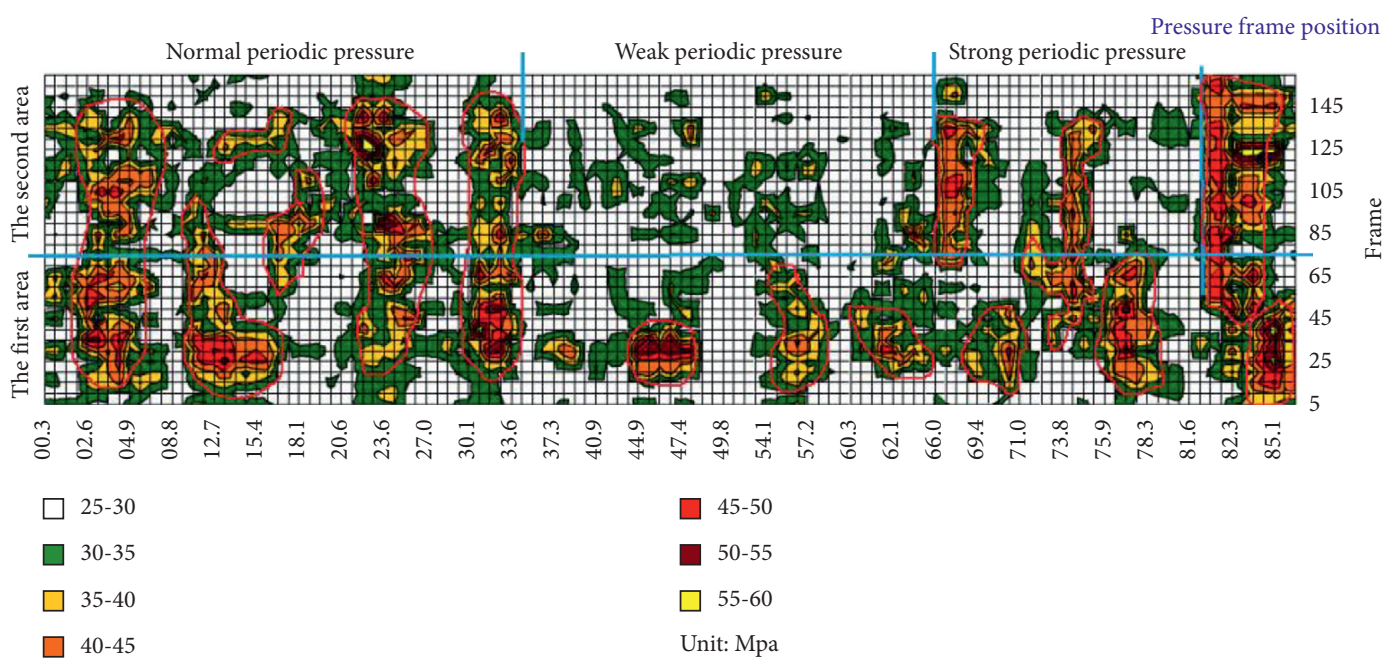

FIGURE 6: Surface map of ground pressure during the support pressing of the 22306 fully working face.

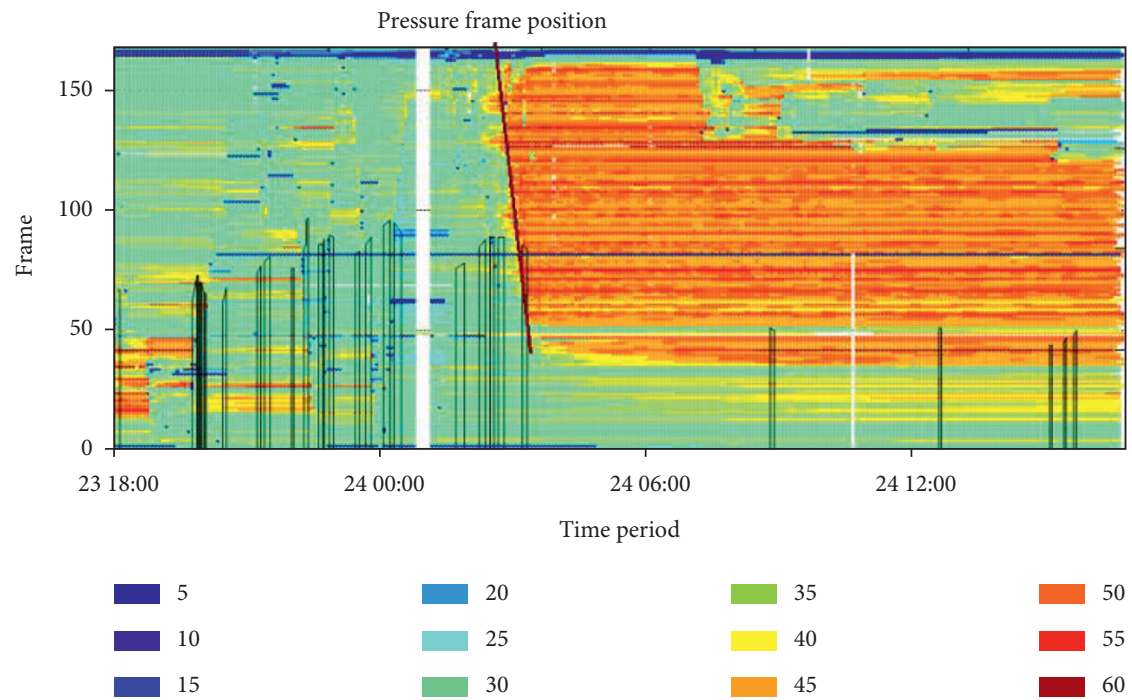

Figure 7: Real-time map of ground pressure during support pressing in the 22306 working face. 
plate, which is simplified to be the displacement boundary condition. It can move in the $X$-direction, and the $Y$-direction is a fixed hinged support; that is, $v=0$.

Boundary conditions on both sides: The boundary conditions on both sides of the model are simplified to be displacement boundary conditions, which can move in the $Y$-direction and with fixed hinged support in the $X$ direction; that is, $u=0$.

The deformation and failure models of the coal and rock mass in the model are all Mohr-Coulomb models. The mechanical parameters of each coal and rock layer in the numerical model are shown in Table 1.

During the process of mining the lower coal seam, the main concern is the coal pressure behavior law before and after the working face advances to the upper goaf boundary pillar. Therefore, to simplify the calculations, the one-time excavation strategy is adopted for the upper coal seam and forms the stope structure after the goaf is stabilized. For the initial mining stage of the lower coal seam, an excavation step distance of $20 \mathrm{~m}$ is adopted. When the working face advances to a distance of $20 \mathrm{~m}$ from the boundary coal pillar of the upper goaf, the excavation step distance of the lower coal seam is reduced to $5 \mathrm{~m}$, and each excavation iteration is 150,000 steps.

4.2. Simulation Analysis of Upper Coal Seam Mining. To study the influence of the goaf boundary coal pillar formed after the mining of the 22 upper coal seam on the mining of the lower coal seam, the overburden of working face after the excavation of the upper coal seam collapses. The resulting displacement and stress fields are shown in Figure 8.

It can be seen from Figures 8(a) and 8(b) that, after the excavation of the upper coal seam, the coal and rock structure above the goaf forms an overlapping rock beam structure with the goaf boundary coal pillar as the supporting point. It can then be seen from Figure 8(c) that the boundary coal pillar, as the supporting point of the stable rock beam structure, is in a state of increased stress.

4.3. Simulation Analysis of Lower Coal Seam Mining. The following are cases that have been simulated considering the mining of the lower coal seam, with the aim of studying the influence of the upper goaf boundary pillar on the mining of the 22 coal seam.

The first simulation considered the excavation of the lower coal seam when it is $20 \mathrm{~m}$ from the goaf boundary coal pillar. When the lower coal seam was excavated and the coal face was $20 \mathrm{~m}$ away from the boundary pillar of the goaf, caving of the overlying rock occurred. The characteristics of the resulting displacement and stress fields are shown in Figure 9. We see from Figure 9(a) that the coal layer structure above the goaf of the upper coal seam is still a relatively stable lap rock beam structure, while the lower coal seam has formed a stable masonry rock beam structure above the coal face following the mining. As can be seen from Figure 9(b), in front of the working face of the lower coal seam, it is in a state of significant stress increase near the boundary coal pillar, but the two areas of increased stress are relatively independent, without overlap.

The next simulation considered the case of excavating the lower coal seam to within $5 \mathrm{~m}$ of the goaf boundary pillar, which saw the overburden collapse. The behavior of the displacement and stress fields are shown in Figure 10. It can be seen from Figure 10(a) that the coal and rock structure above the goaf of the upper coal seam is still a relatively stable overlapping rock beam structure. During the mining of the lower coal seam, the area of rock collapse and instability above the working face increases, and the upper strata form a stable rock beam structure. It can be seen from Figure 10(b) that the front of the working face of the lower coal seam is in the area of stress increase, and the stress near the boundary coal pillar also shows an obvious increase in stress, but these two areas of stress increase overlap and the coal and rock above the working face are in a state of obvious stress increase.

The case where the excavation of the lower coal seam was pushed over the boundary coal pillar for $10 \mathrm{~m}$ was simulated. Again, the overburden of the working face collapses, with the resulting displacement and stress fields shown in Figure 11. Figure 11(a) shows that the structure of the coal and rock strata under the goaf of the upper coal seam is unstable. The lower rock stratum presents a cantilever rock beam structure, and the upper rock stratum forms a masonry rock beam structure. It can be seen from Figure 11(b) that the degree of stress increase in the coal and rock body in front of the working face of the lower coal seam was weakened.

4.4. Stress Field Comparison. To further study the influence of the upper goaf boundary pillar on the mining of the 22 coal seam as outlined above, the stress state of the mediumgrained sandstone with a thickness of $10 \mathrm{~m}$ above the 22 coal seam at different stages of the mining process was determined and analyzed. The arrangement of measuring points in the medium-grained sandstone is shown in Figure 12.

It can be seen from Figure 13 that the vertical stress in the sandstone layer is about 2.2 MPa before the mining of the upper coal seam. After the mining of the upper coal seam, the vertical stress in the medium-grained sandstone layer below the goaf boundary pillar increases to about $3 \mathrm{MPa}$, and the stress in the sandstone layer below the goaf is in a reduced state. It can then be seen from Figure 14 that after the upper coal seam is excavated, the vertical stress in the sandstone layer in front of the working face of the lower coal seam increases to about $3.5 \mathrm{MPa}$ when it is excavated to within $20 \mathrm{~m}$ of the boundary coal pillar of the goaf and to around $11.5 \mathrm{MPa}$ when it is excavated to within $5 \mathrm{~m}$ of the boundary coal pillar of the goaf. When the lower coal seam is excavated $5 \mathrm{~m}$ into the boundary coal pillar of the goaf, the vertical stress in the medium sandstone layer in front of the working face is about $4 \mathrm{MPa}$.

Therefore, when the lower working face is pushed near the upper goaf boundary coal pillar, the internal stress state of the coal and rock mass under the coal pillar increases significantly, which easily leads to the occurrence 
TABLE 1: Mechanical parameters of the coal and rock strata considered in the numerical model.

\begin{tabular}{|c|c|c|c|c|c|c|c|}
\hline Lithology & Thickness (m) & $\begin{array}{c}\text { Density }(\mathrm{kg} / \\
\left.\mathrm{m}^{3}\right)\end{array}$ & $\begin{array}{c}\text { Elastic } \\
\text { modulus }(\mathrm{MPa})\end{array}$ & Poisson's ratio & Cohesion (MPa) & $\begin{array}{c}\text { Tensile } \\
\text { strength }(\mathrm{MPa})\end{array}$ & $\begin{array}{c}\text { Internal } \\
\text { friction angle }\left({ }^{\circ}\right)\end{array}$ \\
\hline $\begin{array}{l}\text { Carbonaceous } \\
\text { mudstone }\end{array}$ & 5.0 & 2482 & 7700 & 0.21 & 5.60 & 5.60 & 39.3 \\
\hline 22 coal seam & 1.7 & 1290 & 2080 & 0.22 & 1.08 & 1.08 & 28.2 \\
\hline Sandy mudstone & 1.2 & 2482 & 7700 & 0.21 & 5.60 & 5.60 & 39.3 \\
\hline $\begin{array}{l}\text { Medium-grained } \\
\text { sandstone }\end{array}$ & 10.0 & 2430 & 1400 & 0.24 & 9.26 & 9.26 & 24.7 \\
\hline $\begin{array}{l}\text { Fine-grained } \\
\text { sandstone }\end{array}$ & 1.9 & 2360 & 1410 & 0.36 & 4.93 & 4.93 & 33.6 \\
\hline Siltstone & 3.0 & 2494 & 1570 & 0.19 & 8.08 & 8.08 & 31.8 \\
\hline Sandy mudstone & 1.6 & 2482 & 7700 & 0.21 & 5.60 & 5.60 & 39.3 \\
\hline 22 upper coal & 1.5 & 1290 & 2080 & 0.22 & 1.08 & 1.08 & 28.2 \\
\hline $\begin{array}{l}\text { Medium-grained } \\
\text { sandstone }\end{array}$ & 10.0 & 2430 & 14000 & 0.24 & 6.00 & 6.00 & 24.7 \\
\hline Load layer & 5.0 & 2482 & 7700 & 0.21 & 5.60 & 5.60 & 39.3 \\
\hline
\end{tabular}

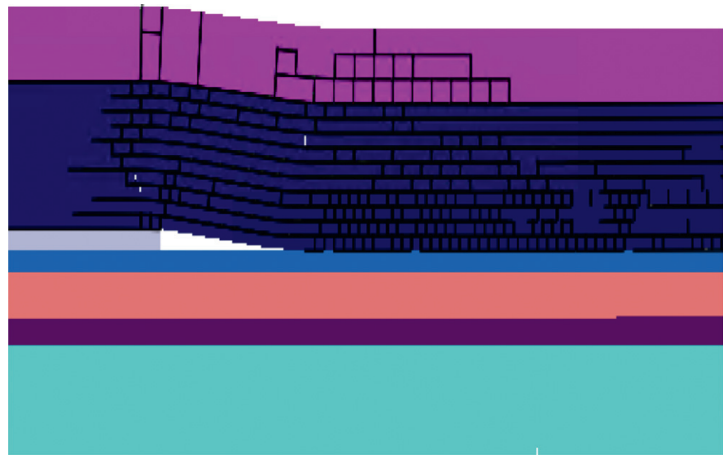

(a)

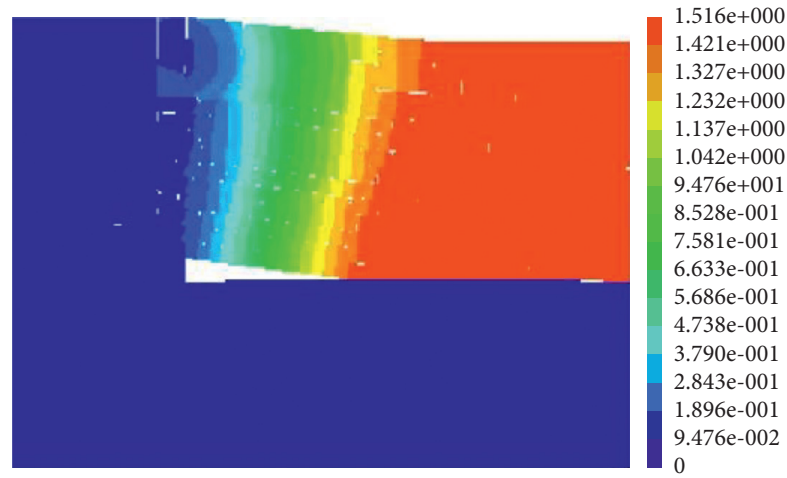

(b)

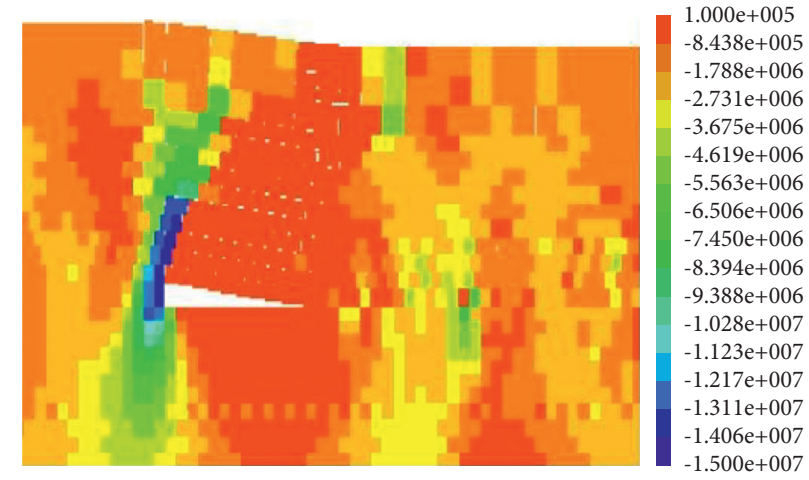

(c)

FIGURE 8: The situation surrounding the mining of the upper coal seam. (a) Collapse of rock mass. (b) Nephogram of stope displacement. (c) Vertical stress cloud map of stope.

of dynamic pressure disasters. The cut roof, main withdrawal channel, and upside coal pillar left by the upper coal mining will transfer the stress from the upper strata to the lower strata, which will lead to a concentration of stress and potentially accidents involving hydraulic support being crushed or roof falls during the lower coal mining process.

\section{Working Face Pressure Mechanism and Prevention Countermeasures}

5.1. Theoretical Analysis of the Working Face Support Pressing Mechanism. The process of fully mechanized shallow coal seam mining which involves the working face passing through the overlying goaf often sees dynamic mine pressure 


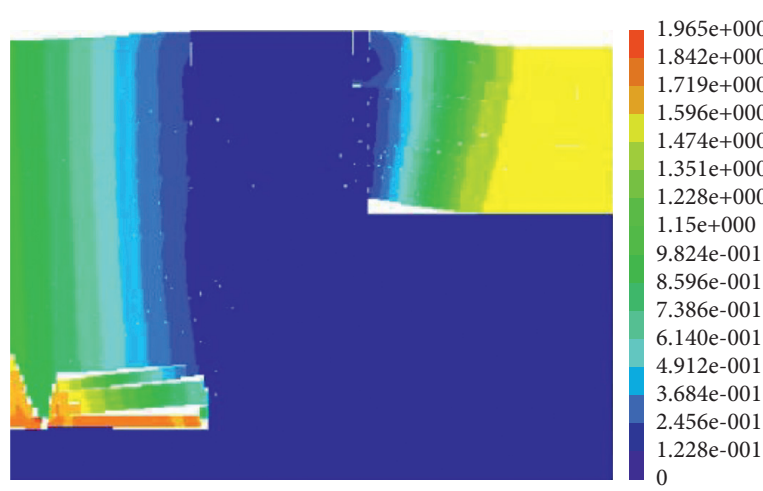

(a)

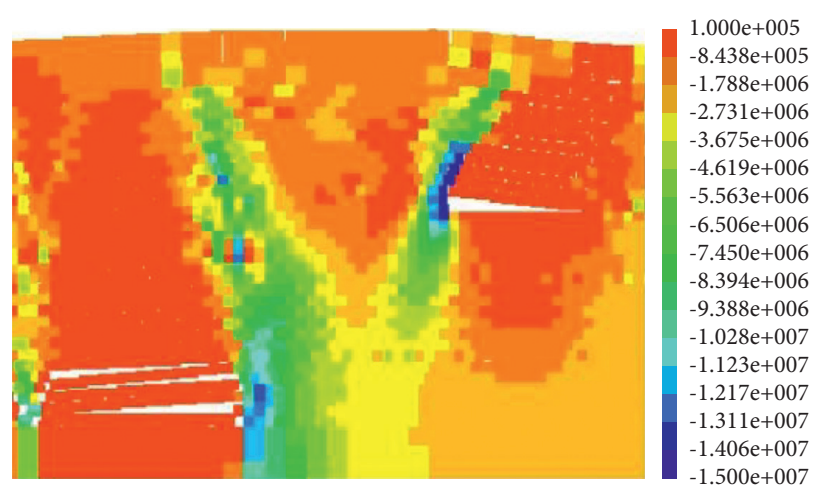

(b)

Figure 9: Evolution of displacement and stress in coal seam mining for the case where the lower coal seam is excavated with the coal face $20 \mathrm{~m}$ from the boundary pillar of the goaf. (a) Nephogram of stope displacement. (b) Vertical stress cloud map of stope.

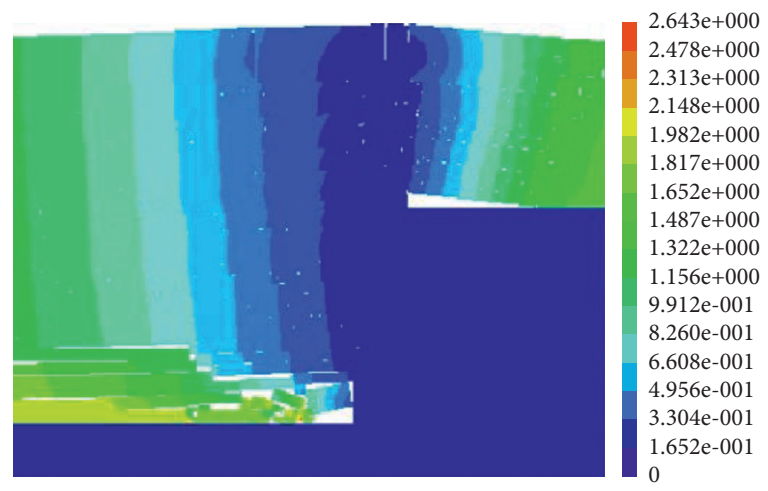

(a)

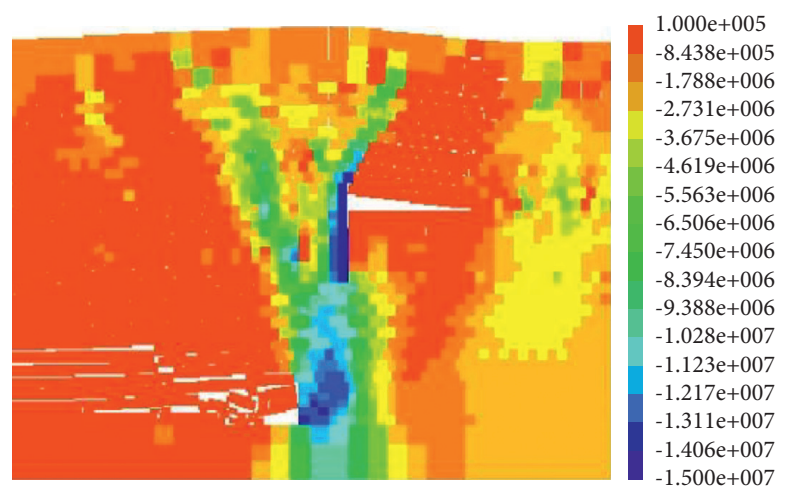

(b)

FIgURE 10: Evolution of displacement and stress in coal seam mining for the case where the lower coal seam is excavated with the coal face $5 \mathrm{~m}$ from the boundary pillar of the goaf. (a) Nephogram of stope displacement. (b) Vertical stress cloud map of stope.

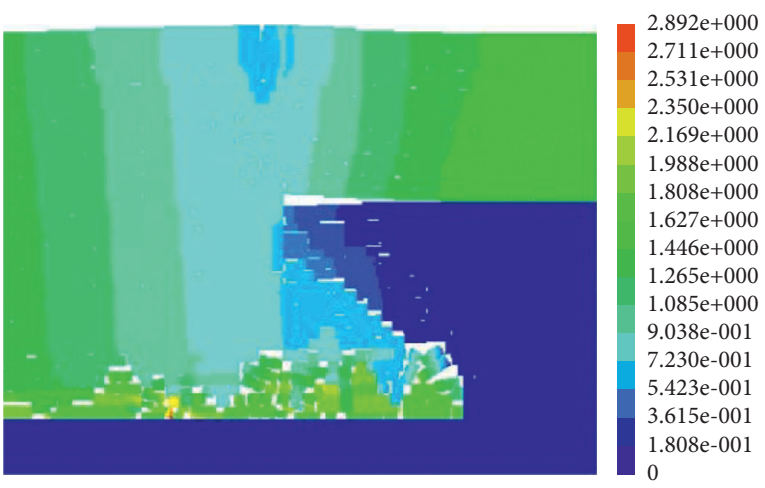

(a)

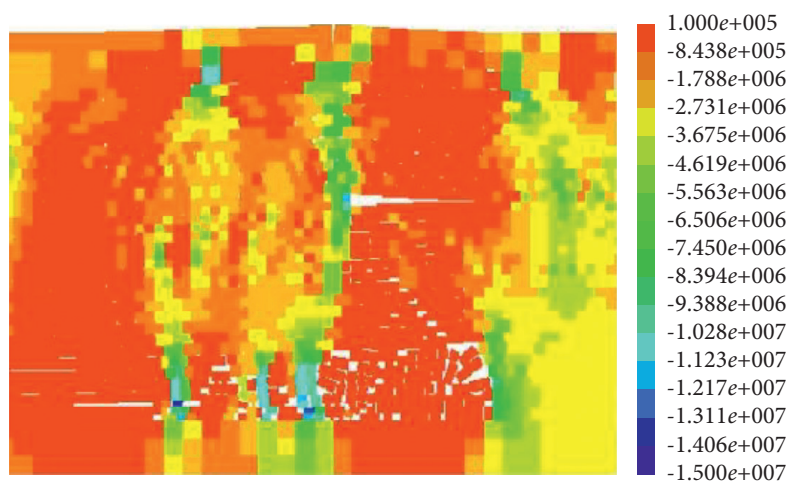

(b)

FIGURE 11: Evolution of displacement and stress in coal seam mining for the case where excavation of the lower coal seam was pushed over the boundary coal pillar by $10 \mathrm{~m}$. (a) Nephogram of stope displacement. (b) Vertical stress cloud map of stope.

appearing in the coal pillar. It is, therefore, necessary to study the activity law of the overlying strata. As shown in Figure 15, in the normal mining process of the 22306 working face, the pressure arch of the working face is formed by rock block $\mathrm{B}$ and rock block $\mathrm{C}$. After the mining of the 22 upper coal seam, 301 working face is completed, a pressure arch is formed in the cutting area by rock blocks D and E. With the advance of the 22306 working face towards the goaf of the overlying working face, the pressure arch of the lower working face is gradually superimposed on that of the upper coal cutting, leading to a large pressure arch being formed. The front foot of the arch is supported on the upper 


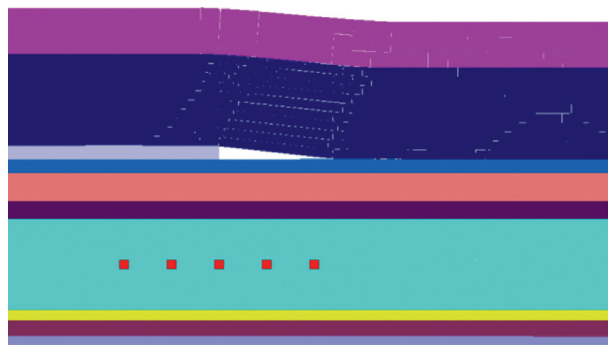

Figure 12: Layout of the measuring points in the stope.

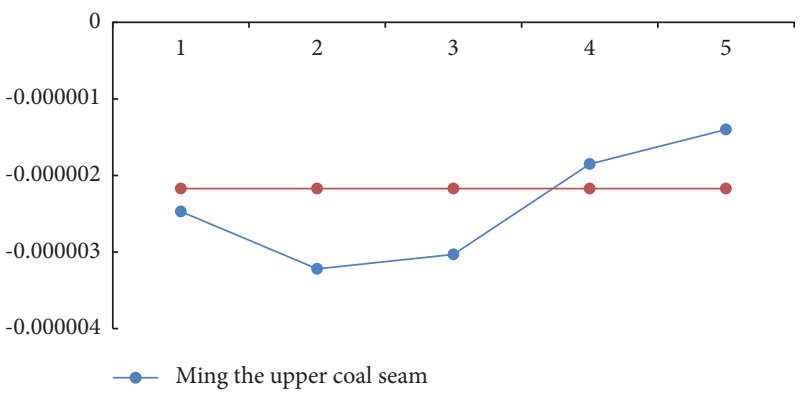

FIGURE 13: Comparison of vertical stress before and after excavation of upper coal seam.

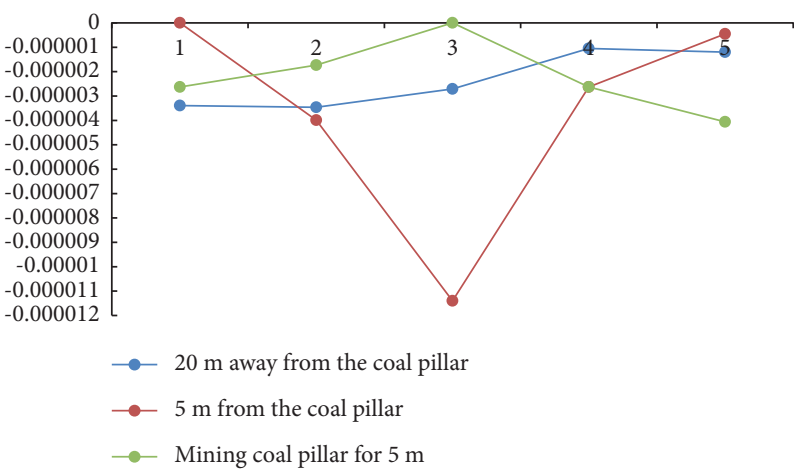

FIGURE 14: Comparison of vertical stress of the lower coal seam mining.

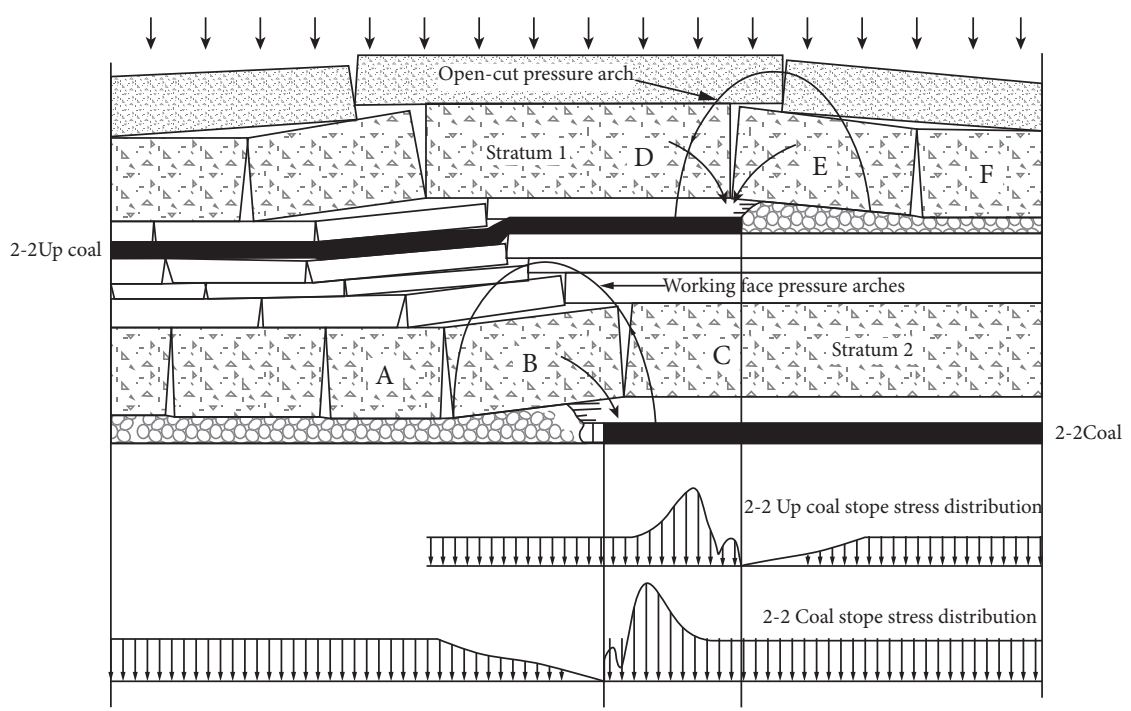

(a)

Figure 15: Continued. 


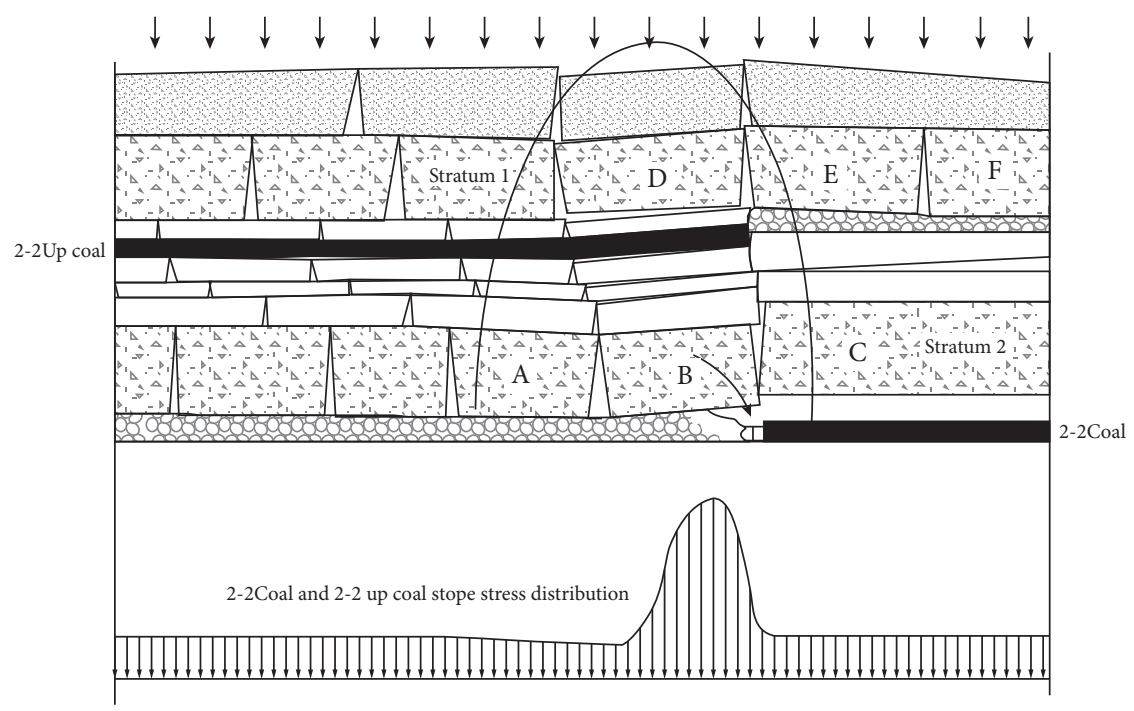

(b)

FIGURE 15: Movement diagram of key strata during the process of a fully mechanized face passing through the overlying goaf.

coal-rock block E, and the back foot is supported on the lower coal-rock block B. At this point, the mine pressure intensifies, leading to serious rib spalling of the working face, and the width of the plastic zone increases. When the coal wall and support in the lower coal plastic zone cannot bear the weight of the overburden pressure arch, a roof fall accident will occur [22].

Through this analysis, rock blocks D and E are seen to be the key rock blocks for controlling the strata pressure behavior when the coal pillar comes out of the lower coal mining face. Therefore, the analysis of the stability of the two key rock blocks is the key to understanding the dynamic strata pressure mechanism of the coal pillar in the lower fully mechanized coal mining face.

5.2. Control Measures. We employ domestically developed coal mine hydraulic fracturing technology instead of traditional directional drilling of a deep hole for presplitting blasting to cover the whole working face coal. When using hydraulic fracturing pressure relief on the key layer, the borehole trajectory can be accurately controlled in terms of the effective fracturing length, where great fracturing cracks extend the range of the working face hard roof fracturing treatment. This process has obvious advantages in terms of technology, economy, and environmental protection.

\subsubsection{Principle of Directional Long Drilling Subsection Hy-} draulic Fracturing Technology. This paper proposes the adoption of double-seal single-card multipoint drag pipe string segment-hydraulic technology. Double-seal singlecard more drag type roof section working principle of the hydraulic fracturing technology for when you are done with the directional drilling construction and after fracturing tool string into the specified location, by double packer single card fracturing target horizon, using the balance in the packer design pressure relief channel, realized the high- pressure pipe string of fracturing fluid and packer pressure balance (Figure 16).

When the high-pressure fracturing fluid reaches $3 \mathrm{MPa}$, the packer is completely set. When the pressure continues until $5 \mathrm{MPa}$, the flow limiter is opened to realize the fracturing process for the required section. During the fracturing process, high-pressure fluid is continuously injected into the roof strata, where the force from the increased water pressure acts on the strata. When the pressure is greater than the formation fracture pressure, the elastic formation can be released in the form of kinetic energy, resulting in vibrations caused by the compression fracture of the rock mass. The dynamic phenomenon sees the rock produce new fracture systems, overburden the overall integrity, and reduce its strength. When the first stage of fracturing is completed, the pumping is shut down and drainage is allowed to relieve pressure, where the packer automatically springs back to its original configuration. The directional drill is then used to move the high-pressure pipe string to the designed position to carry out the second stage of the fracturing process. The fracturing process for the designated section is then done for successive segments. The adjacent sections form continuous rock strata fractures in three dimensions to realize the effective weakening of the hard roof of the coal seam.

5.2.2. Treatment of Coal Pillar Weakening in Close Overlying Areas. Figure 17 shows how directional long drilling and sublevel hydraulic fracturing was adopted when the goaf pillar of the 31305 mining face, which overlies the 22304 mining face, was excavated. According to the measurements of the compaction of the strong coal caused by the overlying remaining coal pillars in the coal face, it can be seen that the hydraulic support is largely destroyed within $40 \mathrm{~m}$ of the remaining coal pillars on the mining face. In order to weaken the roof between the 22 and 31 coal seams in advance to promote roof collapse ahead of time, and to avoid the 


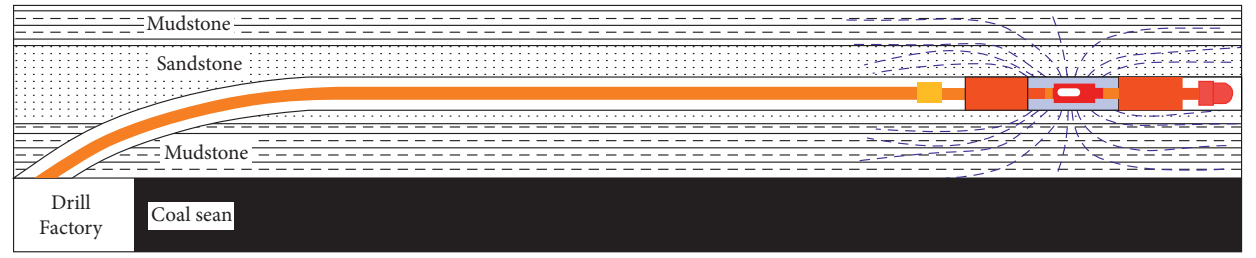

(a)

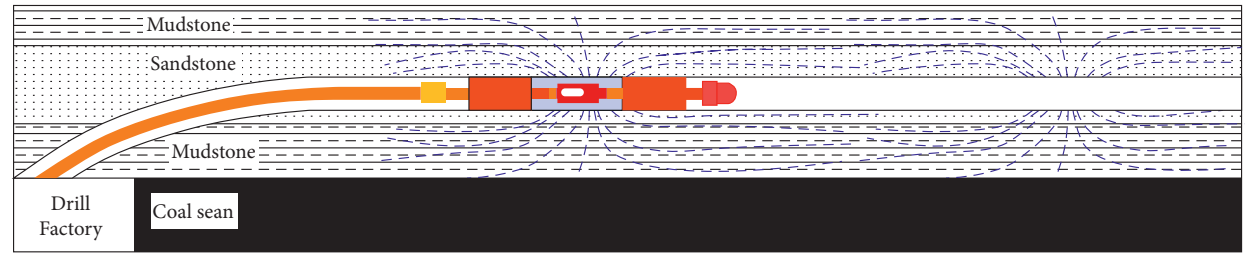

(b)

FIGURE 16: Principle of multipoint drag staging hydraulic fracturing. (a) Multipoint drag staging hydraulic fracturing of the first stage of the fracturing process. (b) The second stage of the multipoint drag hydraulic fracturing process.

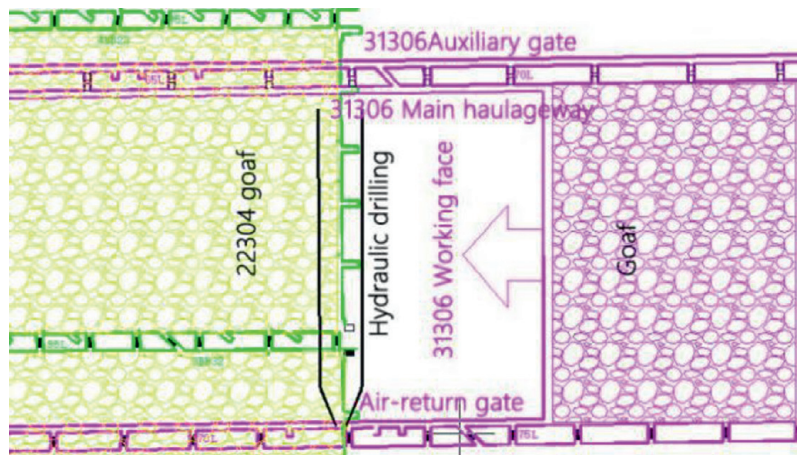

FIgURE 17: Location of the hydraulic fracturing boreholes in the 31305 mining face.

concentrated stress from the rotating collapse of the overlying coal pillar, the support is pressured.

In order to ensure the effectiveness of caving filling, and to ensure the uniform extension and weakening effect of the fracturing, the fracturing boreholes are designed to be arranged in the middle of the rook's basic roof finegrained sandstone, that is, a position $18 \mathrm{~m}$ from the coal seam roof. According to the mechanical characteristics of the rock strata in the study area, the distribution of key strata can be identified by the key strata identification theory. Aiming at the middle and lower-key strata, the cave height of the roof rock is made to fill the goaf through advanced weakening, which forms an effective support for the overburden rock and weakens or eliminates the overburden dynamic load effect. Combined with the principle of rock breaking and expansion, the formula for the caving height required to fill the goaf with overlying strata is as follows.

$M$ is the height of the overlying layer which is broken and $K p$ is the breaking expansion coefficient after rock crushing. Taking $3.5 \mathrm{~m}$ of the $3-1$ coal seam mining height being broken and applying a hulking coefficient of 1.2, we calculate that, for the fully mined-out area, $17.5 \mathrm{~m}$ of the overlying strata is required to guarantee the caving filling.
The borehole is arranged to be $35 \mathrm{~m}$ in front of the coal pillar and $25 \mathrm{~m}$ in front of the coal extraction pillar. The finegrained sandstone layer is $20 \mathrm{~m}$ away from the roof of the 3-1 layer of coal. The borehole profile position is shown in Figure 18, where the hole diameter is $96 \mathrm{~mm}$, the drilling length is $280 \mathrm{~m}$, and the fracturing is arranged over 6 stages.

(1) The Application Effect Comparison of the Same Fully Mechanized Mining Face. Based on real-time downhole monitoring and support data acquisition results, a cloud diagram of the support resistance variation in the process of working stoping before and after the fracturing drilling site of the four coupled roadways along the 31305 return air duct is shown in Figure 19. It is noted that when the working face is stoped at the affected range of fracturing, the overall pressure decreases, the periodicity of the cut pressure is not obvious, and the cut pressure range decreases.

(2) The Application Effect Comparison of Different Mining Faces. The ore pressure comparison was between the fracture-affected area of working face 31305 and the corresponding area of working face 31304 . It can be seen from the table that the average pressure stepping distance of the 31304 working face in the corresponding area is $16.3 \mathrm{~m}$, and the pressure range is distributed between the 35 and 155 hydraulic supports. When the 31305 working face advances to an area influenced by hydraulic fracturing, the average pressure step distance is $9.6 \mathrm{~m}$, decreasing by $41.1 \%$, with the pressure range basically between the 70 and 135 hydraulic supports. When the corresponding position is not fractured, the dynamic load coefficient of the hydraulic support is between 1.15 and 1.36, with an average of 1.29. After the hydraulic fracturing of the working face, the dynamic load coefficient of the support is between 1.05 and 1.26, with an average of 1.15 , a reduction of $10.8 \%$. No obvious floor heave occurred in the tail of the working face, and no obvious floor heave or coal wall heave occurred in the two passageways.

When the water pressure reaches between 16.8 and 24.3 $\mathrm{MPa}$, the target rock stratum is fractured, and the high- 


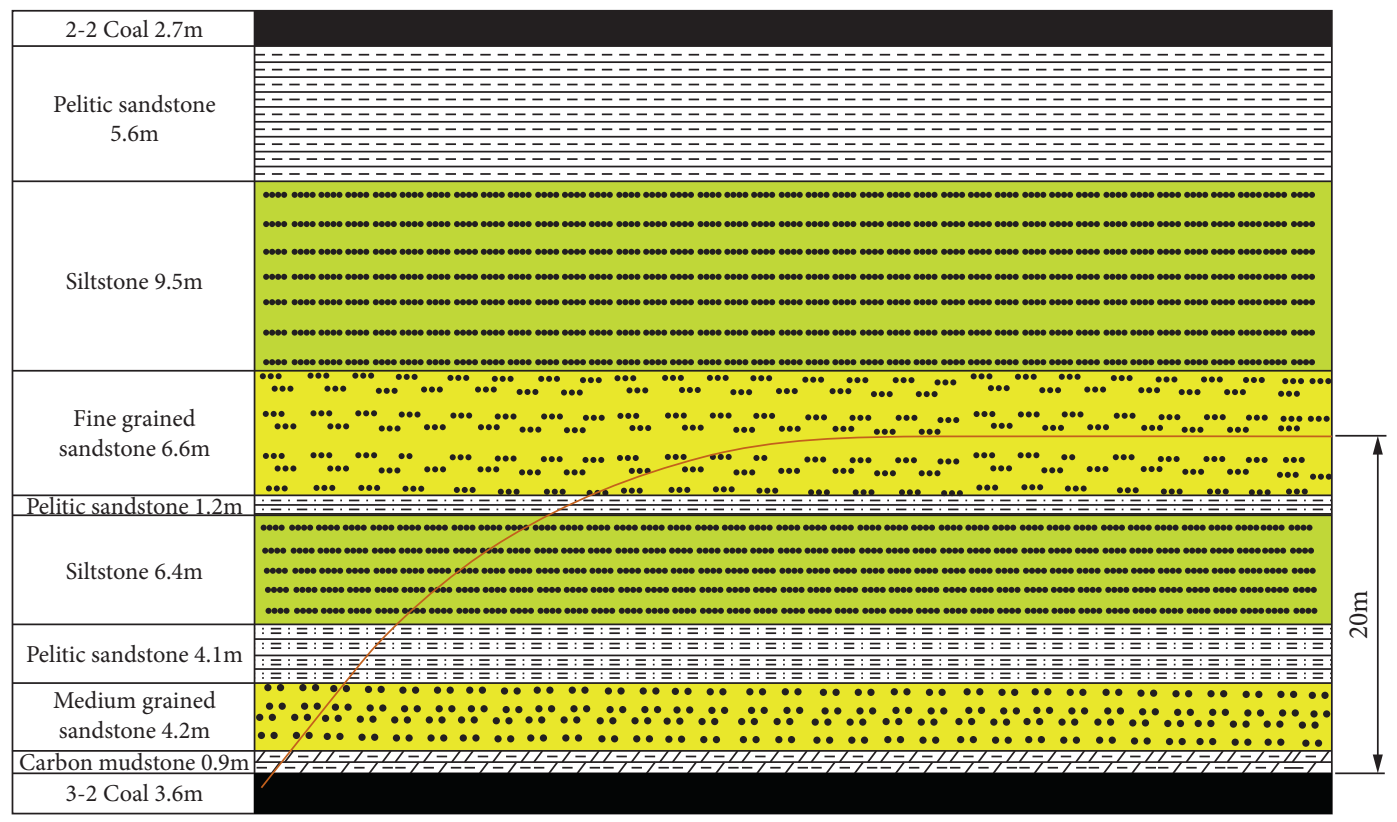

FIgURE 18: Profile of the directional long borehole.

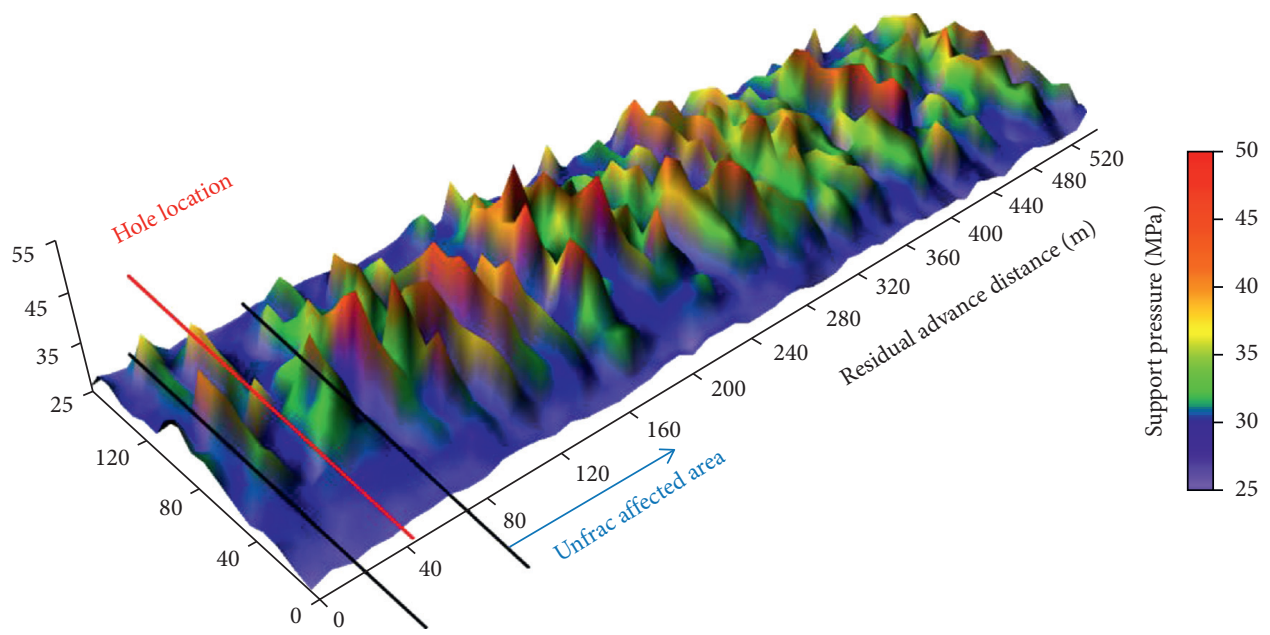

FIGURE 19: Variation characteristics of mine pressure within the fracturing drilling field of 4 combined tunnels with return air in the 31305 mining face.

pressure water injection is continued. The pressure drops periodically to between 3.1 and 9.7 $\mathrm{MPa}$. Large fractures and multiple groups of microfractures are formed by the singlestage fracturing. The main fractures and microfractures of multiple boreholes and multiple fracturing sections are distributed over a wide area, which can effectively weaken the hard roof rock within a certain distance. The fracturing effect is shown in Figure 20.

When the 31305 coal mining face passes through $1 \#$ borehole position to the upper coal mining face cut coal pillar position (672 to $707 \mathrm{~m}$ away), the periodic weighting strength is obviously weakened, and the average working resistance during the periodic weighting period is reduced from $38.67 \mathrm{MPa}$ to $34.62 \mathrm{MPa}$, showing a decrease of $10 \%$. After the coal mining face passes through the upper coal mining face cut coal pillar, there is a large periodic weighting, and the average working resistance of the hydraulic support is $38.87 \mathrm{MPa}$, with a decrease of $10 \%$. When the face is pushed from $720 \mathrm{~m}$ to $739 \mathrm{~m}$, that is, when it is located in the presplitting pressure relief zone of 2\# borehole with high-pressure water, the periodic weighting strength is weakened, and the average working resistance of the hydraulic support is $33.84 \mathrm{MPa}$, with a decrease of $14.1 \%$. This is shown in Figure 21. It can be seen that the directional long borehole staging hydraulic fracturing on the overlying goaf coal pillar of the working face can reduce the concentrated stress, shorten the step and range of the periodic weighting, reduce the periodic weighting strength, and avoid the occurrence of frame crushing and roof falling accidents. 


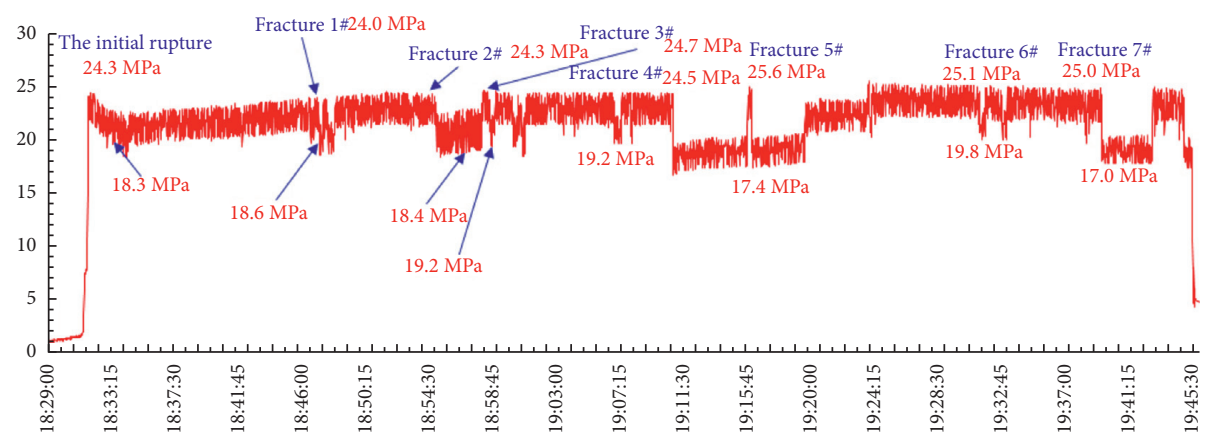

Figure 20: Analysis of the fracturing effect.

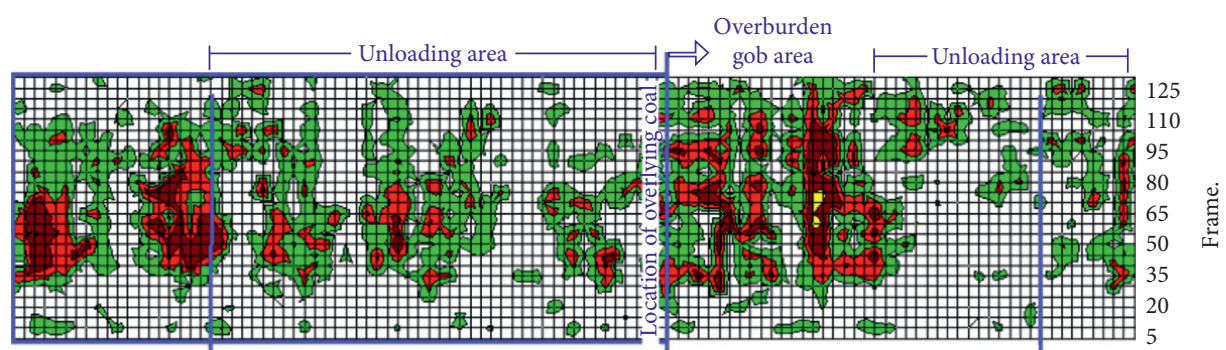

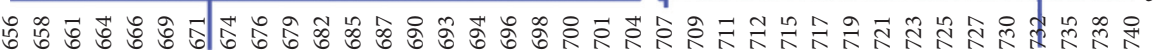

Borehole position \# $1 \quad$ Forward distance $(\mathrm{m}) \quad$ Borehole position \# 2

Below 34.2

$34.2-39.4$

$39.4-44.5$
$44.5-49.7$

49.7-55.0

Unit MPa

FIGURE 21: Strata behavior of the 31305 face passing through the overlying coal pillar.

\section{Conclusion}

Through the analysis of the overlying coal pillar in fully mechanized working face, to the overlying rock pressure monitoring data in fully mechanized mining, the motion law and development characteristics of overlying strata of coal pillar in fully mechanized working face are summarized, and the cause and mechanism of crushing are analyzed. The conclusions are as follows:

(1) The pressure step distance and strength of the working face are significantly changed when considering the period before and after the overburden of the close-range goaf. The open cut on the 301 surface of the 22 overburden is $15.6 \mathrm{~m}$. The pressure step distance of hydraulic supports 1 to 70 shows little change, while the pressure distance for hydraulic supports 75 to 168 has significantly increased, with the pressure step distance decreasing to $7.8 \mathrm{~m}$, with a maximum pressure strength of $48 \mathrm{MPa}$ and an average compressive strength of $34 \mathrm{MPa}$. Before pressing the hydraulic support, the normal section of pressure lasts $6.7 \mathrm{~m}$, and the cycle pressure lasts $3.5 \mathrm{~m}$, so the cycle pressure step distance can be calculated to be $10.2 \mathrm{~m}$.

(2) When the pressure arch of the lower coal face gradually overlaps with the pressure arch of the uppercut, a large pressure arch is formed. Rib spalling of the coal face is a serious issue, with the width of the plastic zone increasing. When the coal wall and support of the lower plastic zone cannot bear the weight of the large pressure arch of the overlying strata, roof fall accidents will occur.

(3) Adopting underground directional long borehole staging hydraulic fracturing technology to carry out hydraulic fracturing and pressure relief on the key layer of the overlying concentrated coal pillar in the working face can effectively control the pressure concentration and resolve problems associated with the working face passing through the overlying close coal pillar and goaf.

\section{Data Availability}

The data used to support the findings of this study are included within the article.

\section{Conflicts of Interest}

There are no conflicts of interest regarding the publication of this paper. 


\section{Acknowledgments}

This paper was supported by the State Key Research Development Program of China (Grant no. 2017YFC0804310) and China Postdoctoral Science Foundation (2020M680490).

\section{References}

[1] J. Z. Yang, "Dynamic pressure prevention and control technology of coal mining face with shallow depth and contiguous seams passing through overburden goaf and coal pillars," Coal Science and Technology, vol. 43, no. 6, pp. 9-13+40, 2015.

[2] J. R. Xiao, S. G. Li, B. Zhang et al., "Control technology of dynamic mine strate pressure of fully-mechanized coal mining face under gob left by room and pillar mining of shallow depth seam," Coal Science and Technology, vol. 42, no. 10, pp. 20-23, 2014.

[3] Y. J. Liu, Q. Qi, and A. H. Wang, "Influence of valleys terrain on pressure of fully mechanized working faces in shallow coal seams," Shock and Vibration, vol. 2021, pp. 1-11, Article ID 8880041, 2021.

[4] X. Z. Xie, "Study on the characteristics of strata behavior in shallow seam longwall mining under the room-and-pillar mining goaf," Journal of China Coal Society, vol. 37, no. 6, pp. 898-902, 2012.

[5] H. Tu, F. J. Dou, Z. J. Wan et al., "Strata control technology of the fully mechanized face in shallow coal seam close to the above room-and-pillar gob," Journal of China Coal Society, vol. 36, no. 3, pp. 366-370, 2011.

[6] X. Ding, X.-C. Xiao, D. Wu, and X.-F. Lv, "Mechanical properties and charge signal characteristics in coal material failure under different loading paths," International Journal of Coal Science \& Technology, vol. 6, no. 1, pp. 138-149, 2019.

[7] L. K. Wei, B. Zhang, X. Y. Fu et al., "Support resistance analysis for special roof structures under room mining goaf," Chinese Journal of Rock Mechanics and Engineering, vol. 34, no. 10, pp. 2142-2147, 2015.

[8] Z. Yang, B. Tong, C. C. Huang et al., "Study of caving and fracturing over a longwall panel beneath a goaf mined by room and pillar," Journal of Mining \& Safety Engineering, vol. 30, no. 3, pp. 323-330, 2013.

[9] W. B. Zhu, Study on the Instability Mechanism of Key Strata Structure in Repeat Mining of Shallow Close Distance Seams, China University of Mining and Technology, Xuzhou, China, 2010.

[10] D. Xue, J. Zhou, Y. Liu, and L. Gao, "On the excavationinduced stress drop in damaged coal considering a coupled yield and failure criterion," International Journal of Coal Science \& Technology, vol. 7, no. 1, pp. 58-67, 2020.

[11] S. L. Yang, Z. H. Wang, D. Z. Kong et al., "Evolution process of overburden fracture and determination of support resistance in high stope," Journal of Mining and Safety Engineering, vol. 33, no. 2, pp. 199-207, 2016.

[12] J. Z. Yang, "Research on key mining technology of fully-mechanized working face with $8 \mathrm{~m}$ large mining height," Coal Science and Technoloy, vol. 45, no. 11, pp. 9-14, 2017.

[13] Q. X. Huang and J. W. Du, "Coupling control of pillar stress and surface cracks in shallow coal seam group mining," Journal of China Coal Society, vol. 43, no. 3, pp. 591-598, 2018.

[14] L. B. Ferund, Dynamic Fracture Mechanics, pp. 165-166, Cambridge University Press, Cambridge, UK, 1990.
[15] J. F. Feng, Y. Zhou, K. Z. Zhang et al., "Fracture characteristics of thick key stratum and calculation of shield work load under multiple coal seam mining gobs with shallow depth," Journal of China Coal Society, vol. 35, no. 2, pp. 332-338, 2018.

[16] A. J. Das, P. K. Mandal, R. Bhattacharjee, S. Tiwari, A. Kushwaha, and L. B. Roy, "Evaluation of stability of underground workings for exploitation of an inclined coal seam by the ubiquitous joint model," International Journal of Rock Mechanics and Mining Sciences, vol. 93, no. 3, pp. 101-114, 2017.

[17] J. L. Xu, W. B. Zhu, and J. F. Ju, "Supports crushing types in the longwall mining of shallow seams," Journal of China Coal Society, vol. 39, no. 8, pp. 1625-1634, 2014.

[18] L. Dou, K. Yang, and X. Chi, "Fracture behavior and acoustic emission characteristics of sandstone samples with inclined precracks," International Journal of Coal Science \& Technology, vol. 8, no. 1, pp. 77-87, 2021.

[19] S. S. Chen, "Dynamic mine strata pressure control technology offull-mechanized coal mining face passing through concentrated coal pillars in above seam," Coal Science and Technology, vol. 42, no. 6, pp. 140-143, 2014.

[20] J. F. Ju and J. L. Xu, "Prevention measures for support crushing while mining out the upper coal pillar in close distance shallow seams," Journal of Mining \& Safety Engineering, vol. 30, no. 3, pp. 323-330, 2013.

[21] J. F. Ju, Mechanism and Prevention of Support Crushing Disaster while Mining Out of the Upper Coal Pillar, China University of Mining and Technology, Xuzhou, China, 2013.

[22] H. Wang, X. Fang, F. Du et al., "Three-dimensional distribution and oxidation degree analysis of coal gangue dump fire area: a case study," The Science of the Total Environment, vol. 772, Article ID 145606, 2021.

[23] J. Z. Yang, K. G. Zheng, Z. R. Wang et al., "Advanced weakening treatment technology for dynamic disaster of Hard Roof," Journal of China Coal Society, vol. 45, no. 10, pp. 3371-3379, 2020.

[24] H. D. Li, H. H. Yang, B. Zhang et al., "Control study of strong strata behaviors during the fully mechanized working face out of concentrated coal pillar in a shallow depth seam in proximity beneath a room mining goaf," Journal of China Coal Society, vol. 40, no. S1, pp. 6-11, 2015.

[25] K. Matsui, H. Shimada, and H. Z. Anwara, "Celeration of massive roof caving in a long wall gob using a hydraulic fractuiing," in Proceedings of the 99th International Symposium on Mining Science and Technology, pp. 43-46, Beijing, China, 1999.

[26] G. Cheng, T. Ma, C. Tang, H. Liu, and S. Wang, “A zoning model for coal mining - induced strata movement based on microseismic monitoring," International Journal of Rock Mechanics and Mining Sciences, vol. 94, no. 3, pp. 123-138, 2017.

[27] H. Wang, X. Fang, Y. Li, Z. Zheng, and J. Shen, "Research and application of the underground fire detection technology based on multi-dimensional data fusion," Tunnelling and Underground Space Technology, vol. 109, Article ID 103753, 2021.

[28] F. Du, K. Wang, X. Zhang, C. Xin, L. Shu, and G. Wang, "Experimental study of coal-gas outburst: insights from coalrock structure, gas pressure and adsorptivity," Natural Resources Research, vol. 29, no. 4, pp. 2481-2493, 2020.

[29] S. Di, J. R. Wang, and G. J. Song, "Study on rib spalling characteristics of $8.5 \mathrm{~m}$ height fully-mechanized mining face," Coal Science and Technology, vol. 45, no. 9, pp. 97-102+115, 2017. 
[30] M. Shabanimashcool and C. C. Li, "Analytical approaches for studying the stability of laminated roof strata," International Journal of Rock Mechanics and Mining Sciences, vol. 79, no. 10, pp. 99-108, 2015.

[31] M. K. Hubbert and D. G. Willis, "Mechanics of Hydraulic Fracturing," Mem. - Am. Assoc. Pet. Geol, vol. 18, 1972.

[32] L. Qiu, D. Song, Z. Li, B. Liu, and J. Liu, "Research on AE and EMR response law of the driving face passing through the fault," Safety Science, vol. 117, pp. 184-193, 2019.

[33] L. Qiu, Z. Liu, E. Wang, X. He, J. Feng, and B. Li, "Earlywarning of rock burst in coal mine by low-frequency electromagnetic Radiation," Engineering Geology, vol. 279, Article ID 105755, 2020. 